\title{
EVALUASI PEMANFAATAN MOBILE MARKETING BERBASIS ANDROID MENGGUNAKAN METODE BUYER BLACK BOX PADA PERUSAHAAN RETAIL DI JAKARTA
}

\author{
Diana Novita, ST, MM ; Yunita Sari, ST, MMSI \\ Universitas Persada Indonesia YAI \\ Email:diananovita306@gmail.com; sari_nita@yahoo.com
}

\begin{abstract}
Increasing the use of smartphones in the world to cause mobile marketing to be one way that seriously considered. marketingIndonesia is one of the country with the number of mobile users device large enough.This has led the very often it access to mobile content more extensive the potential to innovate in mobile marketing.Based on the condition is, we are very interested to do an experiment with the theme of mobile marketing with a view and our long term goal is expected to increase our scientific insight in marketing digitally or commonly called e-commerce. Targeted and we are helping the businesses so as to be easily understand and use mobile marketing in. their marketing strategiesIn this research we will use of the black box of a walker kuisioner. and interviews. The purpose of the use of kuisioner and interview to survey smartphone users as well as the business communities so that we can know whether mobile marketing that has been used in business contributed sub stantial revenue for the company. Then we gave them different restrictions success during her life from the results of of the questionnaire was reflected the bank sound assets. So that we get the result evaluation carried out by the that could be used as an ingredient of the ratio of to learning process for the businessmen in particular and to for us to carry out in general . Keywords: mobile marketing, android, marketing strategies, retail business, a method of the black box
\end{abstract}

\begin{abstract}
Abstrak
Meningkatnya penggunaan smartphone di dunia menyebabkan mobile marketing menjadi salah satu cara pemasaran yang sangat dipertimbangkan. Indonesia merupakan salah satu negara dengan jumlah pengguna mobile device yang cukup besar. Hal ini berakibat semakin sering nya akses terhadap konten mobile yang akhirnya potensi lebih luas untuk berinovasi dalam mobile marketing. Berdasarkan kondisi tersebut, kami sangat tertarik untuk mengadakan penelitian dengan tema mobile marketing dengan maksud dan tujuan jangka panjang kami adalah diharapkan dapat menambah wawasan keilmuan kami didalam bidang pemasaran secara digital atau biasa disebut dengan e-commerce. Sedangkan target khusus kami adalah membantu para pelaku bisnis agar dapat dengan mudah memahami dan menggunakan mobile marketing didalam strategi pemasaran mereka. Didalam penelitian ini kami akan menggunakan metode black box dengan alat bantu berupa kuisioner dan wawancara. Tujuan dari penggunaan kuisioner dan wawancara ini untuk mensurvei para pengguna smartphone dan juga para pelaku bisnis agar kami bisa mengetahui apakah mobile marketing yang telah digunakan dalam bisnis memberikan kontribusi pendapatan yang besar bagi perusahaan. Kemudian kami memberikan batasan kesuksesan dari hasil kuisioner tersebut. Sehingga kami mendapatkan hasil evaluasi yang bisa digunakan sebagai bahan perbandingan dan pembelajaran bagi para pelaku bisnis khususnya dan bagi kami pada umumnya.
\end{abstract}

Kata kunci : mobile marketing, android, strategi pemasaran, bisnis retail, metode black box 
P-ISSN : 0216-261X E-ISSN : 2620-9519

\section{PENDAHULUAN}

\section{Latar belakang}

Mobile Marketing adalah saluran komunikasi pemasaran yang baru dengan memanfaatkan telepon selular (smartphone). Pengguna smartphone yang mencapai 65.2 juta pengguna adalah potensi besar untuk mengembangkan mobile marketing di Indonesia. Kehadiran internet telah merevolusi cara menelusuri informasi dan berbelanja produk. Kini teknologi bergerak (mobile technology) diprediksi memiliki dampak yang lebih besar dalam hal kecepatan jangkauan transaksi perdagangan online dan strategi pemasaran diseluruh dunia. Pemanfaatan mobile marketing berbasis android memberikan kemudahan bagi para penggunanya dan juga membuka peluang lebih luas bagi pemilik usahanya. Alfamart sebagai salah satu perusahaan retail besar di Indonesia, saat ini sudah mulai merambah metode pemasarannya melalui media komunikasi online (internet).

\section{Perumusan Masalah}

Setelah melihat dan memahami bagaimana para pelaku bisnis yang belum memanfaatkan metode mobile marketing dalam transaksi bisnis mereka secara maksimal, maka beberapa rumusan permasalahan dalam penelitian ini :

a. Bagaimanakah mengetahui efektivitas dari pemanfaatan mobile marketing itu?

b. Bagaimanakah hasil yang didapatkan jika pemanfaatan mobile marketing dapat digunakan secara maksimal?

\section{Tujuan Penelitian}

Adapun tujuan penelitian ini adalah :

a. Untuk mengetahui bagaimana efektivitas pemanfaatan mobiler marketing pada bisnis retail?

b. Bagaimanakah hasil yang dicapai bagi bisnis retail dengan mrmanfaatkan mobile marketing secara maksimal?

\section{Manfaat Penelitian}

Adapun manfaat dari penelitian ini :

a. Bagi bisnis retail

Untuk mengetahui parameter parameter pengukuran yang mengindikasikan keefektifan dari pemanfaatan mobile marketing yang dimiliki serta bagaimana memaksimalkan mobile marketing dalam transaksi bisnis.

b. Bagi konsumen

Memberikan kemudahaan bagi konsumen dalam berbelanja.

c. Bagi penulis 
Dapat menambah wawasan dan pengembangan ilmu bagi masyarakat pada umumnya, khususnya dalam bidang e-commerce melalui mobile marketing.

\section{METODOLOGI PENELITIAN}

\section{Desain Penelitian}

Desain penelitian yang digunakan adalah penelitian deskriptif atau yang biasa disebut penelitian taksonomik untuk mengeksplorasi dan mengklarifikasi fenomena atau kenyataan sosial melalui deskripsi sejumlah variabel yang berkenaan dengan masalah dan unit yang diteliti. Penelitian deskriptif tidak menggunakan dan tidak melakukan pengujian hipotesis serta tidak dimaksudkan untuk membangun dan mengembangkan perbendaharaan teori. Dalam pengolahan dan analisis data, lazimnya menggunakan pengolahan statistik yang bersifat deskriptif. Dengan metode deskriptif ini dibuat suatu deskripsi secara sistematis, faktual dan akurat mengenai kondisi cara pemanfaatan mobile marketing pada bisnis retail serta mengetahui parameter - parameter ukuran untuk mengetahui keefektifan dari pemanfaatan mobile marketing di dalam transaksi bisnis.
Penetuan Objek Penelitian dan

Responden / Sampel

1. Penentuan objek penelitian pada perusahaan retail yang telah memiliki mobile marketing berbasis android, dalam hal ini adalah Alfamart.

2. Penentuan objek penelitian juga mencakup kepada pengguna dari mobile marketing berbasis android tersebut, dalam hal ini adalah para konsumen Alfamart.

Pengumpulan Data dan Observasi Lapangan

Metode pengumpulan data di akukan secara langsung pada :

1. Model transaksi di Alfamart maupun sebagai riset pendahuluan.

2. Konsumen Alfamart sebagai responden kuisioner.

3. Para karyawan Alfamart sebagai pemegang pelaksanaan transaksi bisnis melalui mobile marketing berbasis android sebagai responden wawancara dan kuisioner.

Lokasi Penelitian

Lokasi penelitian dipusatkan di beberapa Alfamart yang berada di sekitar wilayah Jakarta.

Adapun teknik digunakan dalam penelitian ini adalah secara : 
Jurnal Parameter Volume $\mathbf{3 0}$ No. 2

DOI : doi.org/10.21009/parameter.302.04

P-ISSN : 0216-261X E-ISSN : 2620-9519

1. Studi literature

Studi literature dilakukan dengan cara mengumpukan dan mempelajari segala macam informasi yang berhubungan dengan mobile marketing berbasis android dan juga mengenai bisnis retail.

2. Pengumpulan data kuisioner

Pengumpulan data dilakukan dengan membagikan kuisioner kepada para responden serta wawancara kepada karyawan Alfamart terhadap hasil kuisioner.

3. Pengolahan data
Pengolahan data dilakukan terhadap hasil kuisioner yaitu dengan memberikan bobot terhadap kriteria penilaian pada setiap kategori, kemudian mengalikan dengan banyaknya responden yang memilih kriteria tersebut. Prosentase pada setiap kategori didapatkan dengan mencari bobot terbesar dibagi dengan total responden.

Pengolahan data disini menggunakan metode Buyer Black Box sebagaimana gambar di bawah ini

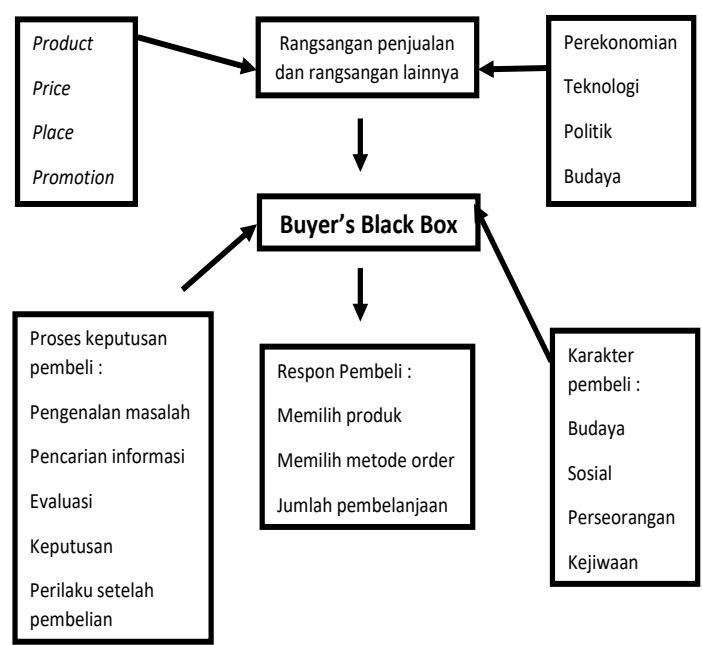

Gambar 1. Model perilaku pembeli (Kotler, 1997)

\begin{tabular}{|c|c|c|c|c|}
\hline \multirow[t]{2}{*}{ Kebudayaan } & \multirow{5}{*}{$\begin{array}{l}\text { Sosial } \\
\text { Kultur, } \\
\text { rujukan } \\
\text { Keluarga } \\
\text { Peran dan } \\
\text { status sosial }\end{array}$} & \multirow{5}{*}{$\begin{array}{l}\text { Personal } \\
\text { Usia } \\
\text { Tahap daur hidup } \\
\text { Jabatan } \\
\text { Keadaan ekonomi } \\
\text { Gaya hidup } \\
\text { Kepribadian }\end{array}$} & \multirow{5}{*}{$\begin{array}{l}\text { Psikologi } \\
\text { Motivasi } \\
\text { Persepsi } \\
\text { Learning } \\
\text { (pembelajaran) } \\
\text { Keperayaan }\end{array}$} & \\
\hline & & & & \\
\hline \multirow{2}{*}{ Kultur } & & & & \\
\hline & & & & Pembeli \\
\hline Subkultur & & & & \\
\hline
\end{tabular}


Gambar 2. Faktor - faktor yang mempengaruhi pembeli

\section{HASIL DAN PEMBAHASAN}

Kuisioner dilakukan terhadap 375 responden yang berada di wilayah Jakarta, dimana responden terdiri dari laki-laki dan perempuan, berusia 17-45 tahun, berlatar pendidikan SMA / sederajat hingga perguruan tinggi, bidang pekerjaan beraneka ragam mulai dari pelajar / mahasiswa, PNS / Dosen / Guru / karyawan, wiraswasta hingga ibu rumah tangga dengan aspek yang dianalisa meliputi 5 (lima) hal, yaitu tangible, reliability, responsif, assurance, dan emphaty. Selain kuisioner, juga dilakukan survey dan wawancara kepada pihak Alfamart untuk mengetahui respon terhadap hasil penilaian responden terkait aplikasi Alfacart.

Berdasarkan hasil kuisioner dan survey serta wawancara yang dilakukan didapatkan hasil sebagaimana di bawah ini:

Evaluasi Pemanfaatan Mobile Marketing (Aplikasi Alfacart) Ditinjau dari Penilaian Masyarakat Untuk mengevaluasi tingkat kepuasan masyarakat terhadap aplikasi Alfacart, penilaian dilakukan dengan memberikan bobot terhadap masing-masing kriteria dengan bobot penilaian sebagai berikut:

$$
\begin{aligned}
& \text { = sangat kecewa } \\
& 2 \text { = kecewa } \\
& 3 \text { = cukup } \\
& 4=\text { puas } \\
& 5=\text { sangat puas }
\end{aligned}
$$

\section{Tingkat Kepuasan Masyarakat} Terhadap Aplikasi Alfacart Ditinjau dari Aspek Tangible

Dari sejumlah responden yang mengetahui aplikasi Alfacart dan melakukan transaksi berbelanja di Alfacart, $38.15 \%$ merasa puas terhadap desain / tampilannya, $42.44 \%$ merasa puas dengan ragam / variasi produk yang ditawarkan didalamnya, 37.50\% merasa puas dengan promo yang ditawarkan, dan $50.18 \%$ merasa cukup puas dengan informasi ketersediaan produk. Berdasarkan prosentase tersebut, hal ini menunjukan bahwa hampir sebagian masyarakat merasa puas dengan desain / tampilan interface aplikasi Alfacart. Hasil analisa tersebut dapat dilihat pada tabel dan grafik di bawah ini. 
Tabel 1. Tingkat Kepuasan Masyarakat Terhadap Aplikasi Alfacart Ditinjau dari Aspek Tangible

\begin{tabular}{|c|c|c|c|c|c|c|c|c|c|c|c|}
\hline \multirow[b]{2}{*}{ Kriteria penilaian } & \multicolumn{2}{|c|}{ Sangat kecewa } & \multicolumn{2}{|c|}{ Kecewa } & \multicolumn{2}{|l|}{ Cukup } & \multicolumn{2}{|c|}{ Puas } & \multicolumn{2}{|c|}{ Sangat puas } & \multirow[b]{2}{*}{ Total responden } \\
\hline & \begin{tabular}{c|} 
Jumlah \\
responden
\end{tabular} & Bobot & $\begin{array}{c}\text { Jumlah } \\
\text { responden }\end{array}$ & Bobot & Jumlah responden & Bobot & $\begin{array}{l}\text { Jumlah } \\
\text { responden }\end{array}$ & Bobot & $\begin{array}{l}\text { Jumlah } \\
\text { responden }\end{array}$ & Bobot & \\
\hline Desain / tampilan & 1 & 1 & 14 & 28 & 101 & 303 & 103 & 412 & 51 & 255 & 270 \\
\hline Ragam / variasi produk & 1 & 1 & 8 & 16 & 108 & 324 & 115 & 460 & 39 & 195 & 271 \\
\hline Promo & 5 & 5 & 29 & 58 & 113 & 339 & 105 & 420 & 28 & 140 & 280 \\
\hline $\begin{array}{l}\text { Informasi ketersediaan } \\
\text { produk }\end{array}$ & 0 & 0 & 21 & 42 & 140 & 420 & 90 & 360 & 28 & 140 & 279 \\
\hline
\end{tabular}

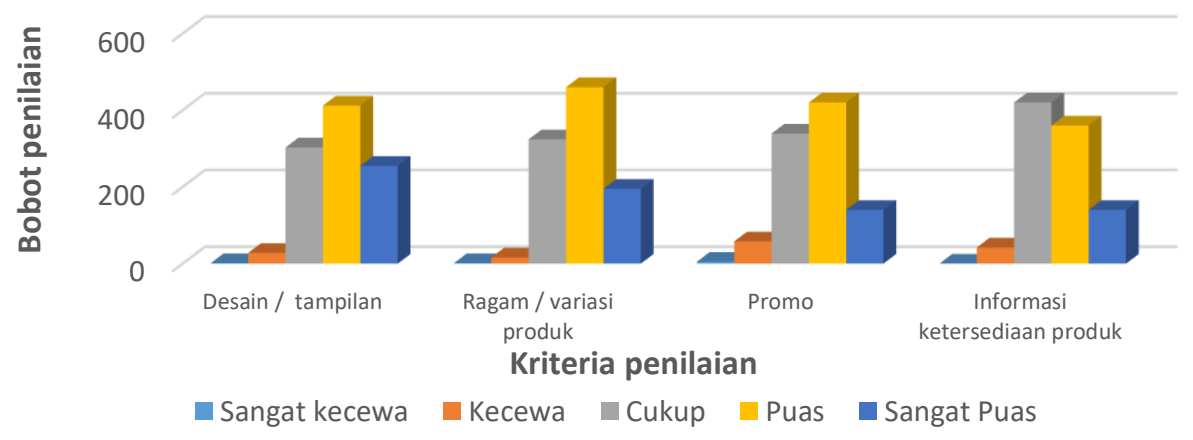

Gambar 3. Tingkat Kepuasan Masyarakat Terhadap Aplikasi Alfacart Ditinjau dari Aspek Tangible

\section{Tingkat Kepuasan Masyarakat}

\section{Terhadap Aplikasi Alfacart Ditinjau} dari Aspek Reliability

Dari sejumlah responden yang mengetahui aplikasi Alfacart dan melakukan transaksi berbelanja di Alfacart, $51.72 \%$ merasa puas dengan kemudahan akses, $42.86 \%$ merasa puas dengan kemudahan penggunaan aplikasi, $36.00 \%$ merasa puas dengan kemudahan bertransaksi, $40.57 \%$ merasa puas dengan kemudahan mendapatkan produk yang ditawarkan, dan $46.86 \%$ merasa puas dengan keamanan \& kenyamanan bertransaksi. Berdasarkan prosentase tersebut, hal ini menunjukan bahwa hampir sebagian masyarakat merasa puas dengan kehandalan aplikasi Alfacart. Hasil analisa tersebut dapat dilihat pada tabel dan grafik di bawah ini 
Tabel 2. Tingkat Kepuasan Masyarakat Terhadap Aplikasi Alfacart Ditinjau dari Aspek Reliability

\begin{tabular}{|c|c|c|c|c|c|c|c|c|c|c|c|}
\hline \multirow{2}{*}{ Kriteria penilaian } & \multicolumn{2}{|c|}{ Sangat kecewa } & \multicolumn{2}{|c|}{ Kecewa } & \multicolumn{2}{|l|}{ Cukup } & \multicolumn{2}{|c|}{ Puas } & \multicolumn{2}{|c|}{ Sangat puas } & \multirow{2}{*}{ Total responden } \\
\hline & Jumlah & Bobot & Jumlah & Bobot & \begin{tabular}{|l|} 
Jumlah responden \\
\end{tabular} & Bobot & Jumlah & Bobot & Jumlah & Bobot & \\
\hline Kemudahan akses & 2 & 2 & 3 & 6 & 52 & 156 & 90 & 360 & 27 & 135 & 174 \\
\hline Kemudahan penggunaan & 1 & 1 & 7 & 14 & 61 & 183 & 75 & 300 & 31 & 155 & 175 \\
\hline Kemudahan bertransaksi & 1 & 1 & 6 & 12 & 84 & 252 & 63 & 252 & 21 & 105 & 175 \\
\hline $\begin{array}{l}\text { Kemudahan mendapatkan } \\
\text { produk yang ditawarkan }\end{array}$ & 1 & 1 & 7 & 14 & 70 & 210 & 71 & 284 & 26 & 130 & 175 \\
\hline $\begin{array}{l}\text { Keamanan dan kenyamaman } \\
\text { dalam bertransaksi }\end{array}$ & 1 & 1 & 4 & 8 & 68 & 204 & 82 & 328 & 20 & 100 & 175 \\
\hline
\end{tabular}

Tingkat Kepuasan Masyarakat Terhadap Aplikasi Alfacart Ditinjau dari Aspek Reliability

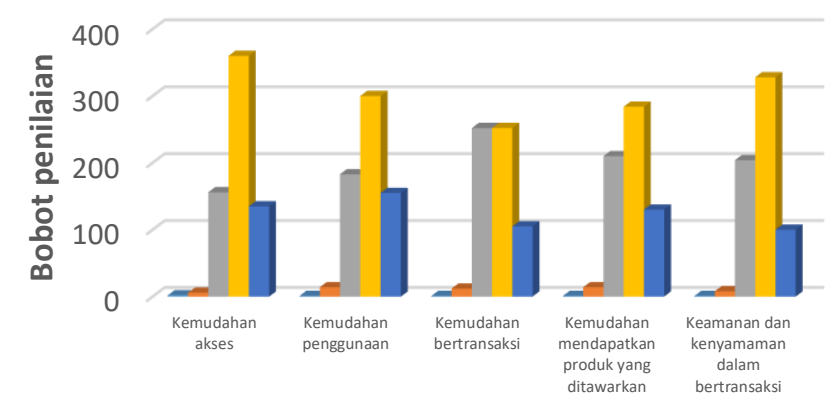

Kriteria penilaian

- Sangat kecewa Kecewa $\quad$ Cukup Puas $\square$ Sangat Puas

Grafik 4. Tingkat Kepuasan Masyarakat Terhadap Aplikasi Alfacart Ditinjau dari Aspek Reliability

\section{Tingkat Kepuasan Masyarakat Terhadap} Aplikasi Alfacart Ditinjau dari Aspek Responsif

Dari sejumlah responden yang mengetahui aplikasi Alfacart dan melakukan transaksi berbelanja di Alfacart, $37.50 \%$ merasa puas dengan proses konfirmasi (pesanan \& pembayaran), dan $52.00 \%$ merasa cukup puas dengan proses pengiriman barang. Berdasarkan prosentase tersebut, hal ini menunjukan bahwa hampir sebagian masyarakat merasa cukup puas bahkan puas dengan respon pihak Alfacart. Hasil analisa tersebut dapat dilihat pada tabel dan grafik di bawah ini.

Tabel 3. Tingkat Kepuasan Masyarakat Terhadap Aplikasi Alfacart Ditinjau dari Aspek Responsif

\begin{tabular}{|c|c|c|c|c|c|c|c|c|c|c|c|}
\hline \multirow{2}{*}{ Kriteria penilaian } & \multicolumn{2}{|c|}{ Sangat kecewa } & \multicolumn{2}{|c|}{ Kecewa } & \multicolumn{2}{|l|}{ Cukup } & \multicolumn{2}{|c|}{ Puas } & \multicolumn{2}{|c|}{ Sangat puas } & \multirow{2}{*}{ Total responden } \\
\hline & Jumlah & Bobot & Jumlah & Bobot & Jumlah responden & Bobot & Jumlah & Bobot & Jumlah & Bobot & \\
\hline $\begin{array}{l}\text { Proses konfirmasi (pesanan } \\
\text { dan pembayaran) }\end{array}$ & 0 & 0 & 11 & 22 & 86 & 258 & 66 & 264 & 13 & 65 & 176 \\
\hline Proses pengiriman barang & 1 & 1 & 11 & 22 & 91 & 273 & 63 & 252 & 9 & 45 & 175 \\
\hline
\end{tabular}


Evaluasi Pemanfaatan Mobile Marketing (Aplikasi Alfacart) Ditinjau dari Pihak Alfamart

Untuk mengetahui respon dari pihak Alfamart terhadap hasil penilaian responden terkait aplikasi Alfacart, wawancara dilakukan terhadap 2 (dua) orang Supervisor di Alfamart Tebet dan 2 (dua) orang Supervisor di Alfamart Tanjung Priok. Wawancara yang dilakukan meliputi 5 (lima) aspek, yaitu tangible, reliability, responsif, assurance, dan emphaty. Adapun hasil wawancara yang dilakukan dapat dilihat pada penjelasan di bawah ini.

\section{Tingkat Kepuasan Masyarakat}

Terhadap Aplikasi Alfacart Ditinjau dari Aspek Tangible

- Terkait desain / tampilan aplikasi Alfacart, pihak Alfamart akan selalu berusaha untuk mengupgrade website maupun mobile app (aplikasi Alfacart) agar dapat memberikan kemudahan bagi penggunanya, bahkan kedepannya pihak Alfamart berencana menambahkan beberapa fitur baru seperti pemberian kupon sehingga dapat merangsang minat masyarakat untuk berbelanja melalui aplikasi Alfacart.
- Terkait ragam / variasi produk yang ditawarkan didalamnya, ke depannya pihak Alfamrt berencana menyediakan beragam fasilitas pembayaran seperti listrik, telpon, kartu kredit, dan lain - lain di dalam aplikasi Alfacart, sehinggamemudahkan masyarakat dalam melakukan berbagai macam pembayaran.

- Terkait promo yang ditawarkan, saat ini pihak Alfamart membuat official Alfacart melalui beberapa channel seperti LINE, facebook, istagram, dan lain - lain.

- Terkait informasi ketersediaan produk, pihak Alfamart berusaha memperbaiki dan mengembangkan aplikasi ke arah yang lebih baik terutama dalam hal mengupdate informasi ketersediaan produk.

\section{Tingkat Kepuasan Masyarakat}

\section{Terhadap Aplikasi Alfacart Ditinjau}

\section{dari Aspek Reliability}

- Terkait kemudahan akses dan penggunaan aplikasi, pihak Alfamart berusaha membuat website maupun aplikasi yang memudahkan pengunjung berinteraksi di dalamnya, termasuk kecepatan mengakses sehingga 
tidak terjadinya masalah pada saat bertransaksi.

- Terkait kemudahan bertransaksi, dalam memudahkan pendataan terhadapa transaksi yang dilakukan, pihak Alfamart mengharuskan pengunjung untuk membuat akun terlebih dahulu sebelum melakukan transaksi.

- Terkait kemudahan mendapatkan produk yang ditawarkan, pihak Alfamart selalu berusaha berkoordinasi dengan pihak Vendor dalam penyediaan produk, sehingga produk yang ditawarkan senantiasa tersedia.

- Terkait keamanan \& kenyamanan bertransaksi, setiap transaksi yang dilakukan melalui aplikasi maupun website, pihak Alfamart menyediakan opsi pembayaran langsung di gerai Alfamart maupun tunai saat barang diterima (cash on delivery). Selain itu pelanggan juga dapat mengambil barang pesanannya langsung di gerai Alfamart mana saja yang terdekat dengan lokasi.

\section{Tingkat Kepuasan Masyarakat}

Terhadap Aplikasi Alfacart Ditinjau dari Aspek Responsif
- Terkait proses konfirmasi (pesanan \& pembayaran), konfirmasi pesanan yang dilakukan oleh pihak Alfamart tidak hanya melalui email, tetapi juga melalui SMS yang yang telah didaftarkan sebelumnya.

- Terkait proses pengiriman barang, pihak Alfamart senantiasa memperhatikan kepuasan pelanggan salah satunya dalam hal pengiriman barang, dengan mengarahkan pengiriman barang ke gerai Alfamart terdekat dengan lokasi pelanggan.

\section{Tingkat Kepuasan Masyarakat}

Terhadap Aplikasi Alfacart Ditinjau

dari Aspek Assurance

- Terkait pelayanan customer service, pihak Alfamart senantiasa memberikan pelatihan kepada seluruh karyawannya yang dalam hal ini adalah customer service, dimana mereka dituntut untuk selalu bersikap ramah dalam menghadapi complaint pelanggan.

- Terkait kinerja pihak Alfamart, pihak Alfamart senantiasa memberikan pelatihan kepada seluruh karyawannya dalam meningkatkan kinerja karyawan. 
- Tekait keakurasian proses administrasi, pihak Alfamart berusaha melakukan pendataan yang baik dan teliti.

- Terkait penanganan complaint pelanggan, pihak Alfamart senantiasa memberikan pelatihan kepada seluruh karyawannya yang dalam hal ini adalah customer service, dimana mereka dituntut untuk selalu bersikap ramah dalam menghadapi complaint pelanggan.

\section{Tingkat Kepuasan Masyarakat}

\section{Terhadap Aplikasi Alfacart Ditinjau}

\section{dari Aspek Emphaty}

- Terkait perhatian yang diberikan oleh pihak Alfamart kepada pelanggan individu, pihak Alfamart melakukan pengelompokan berdasarkan 2 (dua) kategori yaitu pelanggan individu dan korporasi, namun secara pelayanan yang diberikan tidak dibedakan.
- Terkait kesungguhan pihak Alfmart dalam merespon pelanggan dan waktu respon yang diberikan pihak Alfamart, pihak Alfamart membagi karyawannya dalam beberapa shif agar selalu dapat melayani pelanggan selama 24 jam, dan berusaha memberikan repon cepat atas keluhan maupun pertanyaan pelanggan.

- Terkait dengan perhatian yang sama (tanpa memandang status social) kepada semua pelanggan yang diberikan pihak Alfamart, pihak Alfamart idak pernah membedakan pelayanan yang diberikan kepada semua pelanggannya, baik korporasi maupun individu.

- Terkait mekanisme penanganan complaint pelanggan, pihak Alfamart menyediakan fungsi khusus untuk menangani complaint pelanggan, dimana setiap complaint yang diterima akan langsung ditangani saat itu juga. 


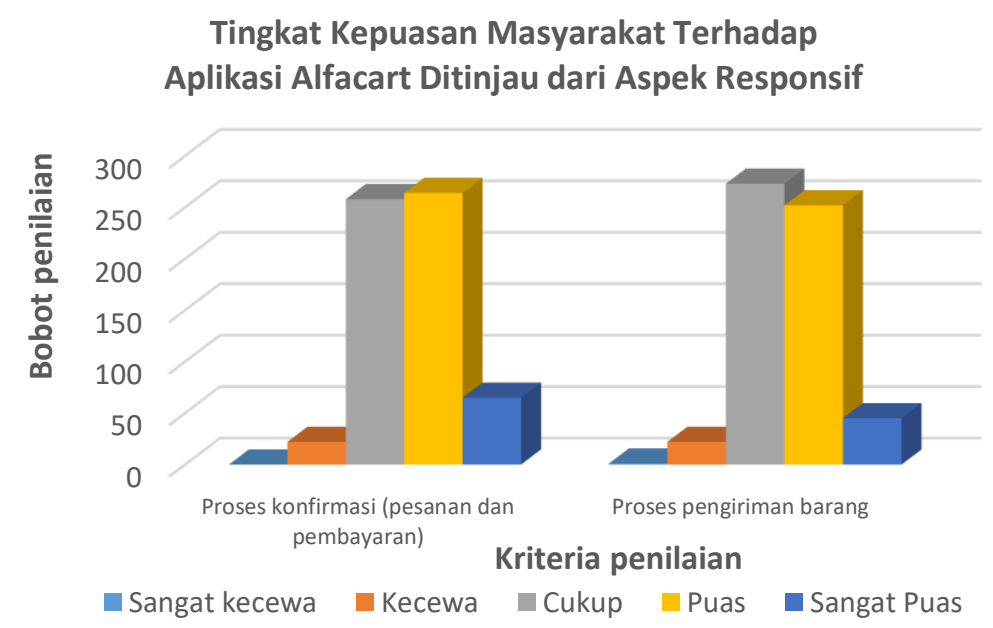

Gambar 5. Tingkat Kepuasan Masyarakat Terhadap Aplikasi Alfacart Ditinjau dari Aspek Responsif

\section{Tingkat Kepuasan Masyarakat \\ Terhadap Aplikasi Alfacart Ditinjau dari Aspek Assurance}

Dari sejumlah responden yang mengetahui aplikasi Alfacart dan melakukan transaksi berbelanja di Alfacart, $47.73 \%$ merasa cukup puas dengan pelayanan customer service, $50.70 \%$ merasa cukup puas dengan kinerja pihak Alfacart, 54.82\% merasa cukup puas dengan keakurasian proses administrasi, dan $47.73 \%$ merasa cukup puas dengan penanganan complaint pelanggan. Berdasarkan prosentase tersebut, hal ini menunjukan bahwa sebagian masyarakat merasa cukup puas dengan pelayanan pihak Alfacart. Hasil analisa tersebut dapat dilihat pada tabel dan grafik di bawah ini.

Tabel 4. Tingkat Kepuasan Masyarakat Terhadap Aplikasi Alfacart Ditinjau dari Aspek Assurance

\begin{tabular}{|c|c|c|c|c|c|c|c|c|c|c|c|}
\hline \multirow{2}{*}{ Kriteria penilaian } & \multicolumn{2}{|c|}{ Sangat kecewa } & \multicolumn{2}{|c|}{ Kecewa } & \multicolumn{2}{|l|}{ Cukup } & \multicolumn{2}{|c|}{ Puas } & \multicolumn{2}{|c|}{ Sangat puas } & \multirow{2}{*}{ Total responden } \\
\hline & Jumlah & Bobot & Jumlah & Bobot & Jumlah responden & Bobot & Jumlah & Bobot & Jumlah & Bobot & \\
\hline Pelayanan Customer Service & 1 & 1 & 21 & 42 & 84 & 252 & 57 & 228 & 13 & 65 & 176 \\
\hline Kinerja pihak Alfacart & 1 & 1 & 14 & 28 & 89 & 267 & 54 & 216 & 18 & 90 & 176 \\
\hline $\begin{array}{ll}\text { Keakurasian } & \text { proses } \\
\text { administrasi } & \\
\end{array}$ & & 0 & 10 & 20 & 91 & 273 & 53 & 212 & 12 & 60 & 166 \\
\hline $\begin{array}{l}\text { Penanganan complaint } \\
\text { pelanggan }\end{array}$ & 2 & 2 & 20 & 40 & 84 & 252 & 61 & 244 & 9 & 45 & 176 \\
\hline
\end{tabular}




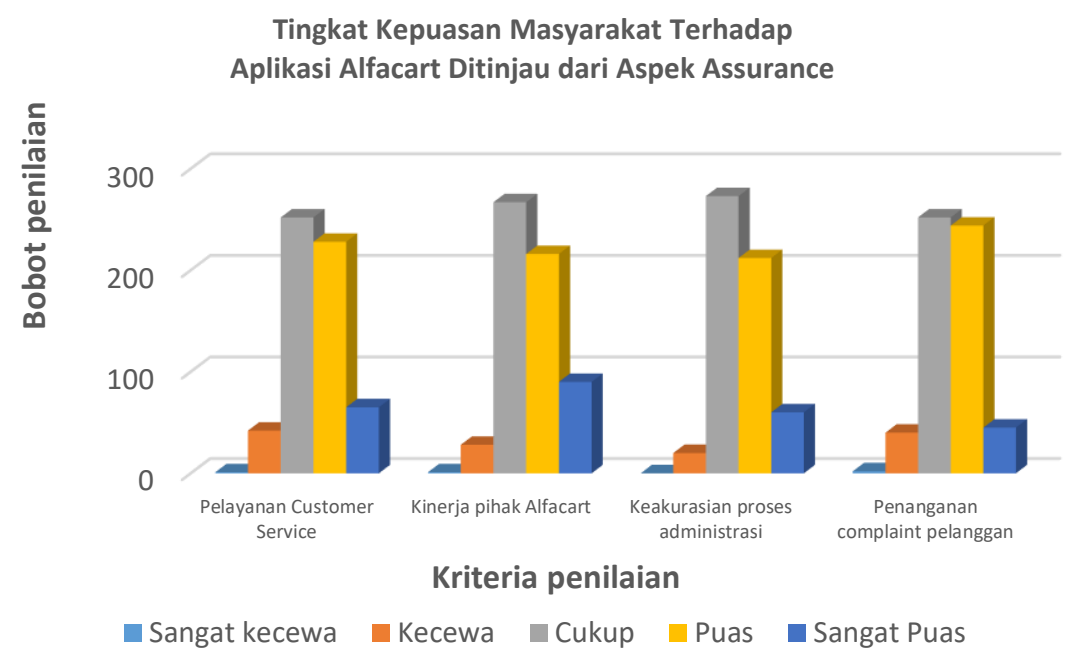

Gambar 6. Tingkat Kepuasan Masyarakat Terhadap Aplikasi Alfacart Ditinjau dari Aspek Assurance

Tingkat Kepuasan Masyarakat

Terhadap Aplikasi Alfacart Ditinjau dari Aspek Emphaty

Dari sejumlah responden yang mengetahui aplikasi Alfacart dan melakukan transaksi berbelanja di Alfacart, $35.63 \%$ merasa puas dengan perhatian yang diberikan oleh pihak Alfacart kepada pelanggan individu, $41.90 \%$ merasa puas dengan kesungguhan pihak Alfcart dalam merespon pelanggan, $35.43 \%$ merasa puas dengan perhatian yang sama (tanpa memandang status social) kepada semua pelanggan yang diberikan pihak Alfacart , 48.00\% merasa cukup puas dengan waktu respon pihak Alfacart, dan 48.00\% merasa cukup puas dengan meknisme penanganan complaint pelanggan. Berdasarkan prosentase tersebut, hal ini menunjukan bahwa sebagian masyarakat merasa cukup puas bahkan puas dengan emphaty pihak Alfacart kepada pelanggan. Hasil analisa tersebut dapat dilihat pada tabel dan grafik di bawah ini.

Tabel 5. Tingkat Kepuasan Masyarakat Terhadap Aplikasi Alfacart Ditinjau dari Aspek Emphaty

\begin{tabular}{|c|c|c|c|c|c|c|c|c|c|c|c|}
\hline \multirow{2}{*}{ Kriteria penilaian } & \multicolumn{2}{|c|}{ Sangat kecewa } & \multicolumn{2}{|c|}{ Kecewa } & \multicolumn{2}{|l|}{ Cukup } & \multicolumn{2}{|c|}{ Puas } & \multicolumn{2}{|c|}{ Sangat puas } & \multirow{2}{*}{ Total responden } \\
\hline & Jumlah & Bobot & Jumlah & Bobot & Jumlah responden & Bobot & Jumlah & Bobot & Jumlah & Bobot & \\
\hline $\begin{array}{l}\text { Perhatian terhadap } \\
\text { pelanggan individu }\end{array}$ & 1 & 1 & 14 & 28 & 78 & 234 & 62 & 248 & 19 & 95 & 174 \\
\hline $\begin{array}{l}\text { Kesungguhan dalam } \\
\text { merespon pelanggan }\end{array}$ & 1 & 1 & 20 & 40 & 68 & 204 & 75 & 300 & 15 & 75 & 179 \\
\hline $\begin{array}{l}\text { Perhatian yang sama (tanpa } \\
\text { memandang status sosia) }\end{array}$ & 2 & 2 & 15 & 30 & 79 & 237 & 62 & 248 & 17 & 85 & 175 \\
\hline Waktu respon & 1 & 1 & 20 & 40 & 84 & 252 & 51 & 204 & 19 & 95 & 175 \\
\hline $\begin{array}{l}\text { Mekanisme penanganan } \\
\text { complaint pelanggan }\end{array}$ & 2 & 2 & 20 & 40 & 84 & 252 & 46 & 184 & 23 & 115 & 175 \\
\hline
\end{tabular}




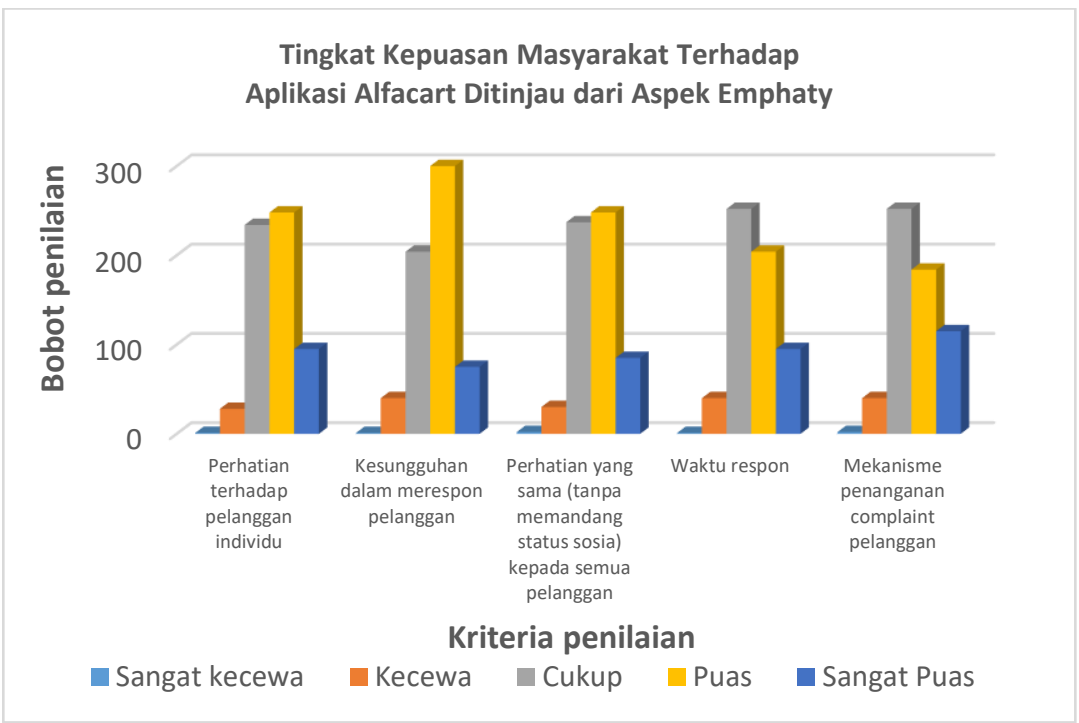

Gambar 7. Tingkat Kepuasan Masyarakat Terhadap Aplikasi Alfacart Ditinjau dari Aspek Emphaty

\section{PENUTUP}

Untuk mengetahui sejauh mana tingkat kepuasan masayarakat terhadap pemanfaatan mobile marketing berbasis Android, dilakukan analisa data yang diperoleh berdasarkan hasil kuesioner dari 375 responden dengan berbagai jenis kelamin, usia dan pekerjaan yang berada di wilayah Jakarta, serta hasil wawancara dengan 4 personil Alfacart yang bertugas di Alfamart Tebet dan Tanjung Priok. Aspek yang dianalisa meliputi tangible, reliability, responsif, assurance, dan emphaty.

- Pada aspek tangible yang meliputi desain/tampilan aplikasi, ragam/variasi produk, promo dan informasi ketersediaan produk, menunjukan $\quad 42.07 \%$ responden merasa puas dengan desain / tampilan interface aplikasi Alfacart.

- Pada aspek reliability yang meliputi kemudahan akses aplikasi, kemudahan penggunaan aplikasi, kemudahan transaksi, kemudahan mendapatkan produk yang ditawarkan serta keamanan dan kenyamaman dalam bertransaksi, menunjukan $44.97 \%$ responden merasa puas dengan kehandalan aplikasi Alfacart.

- Pada aspek responsive yang meliputi proses konfirmasi (pesanan \& pembayaran) dan pengiriman barang, menunjukan $44.75 \%$ responden merasa cukup puas bahkan puas dengan respon pihak Alfacart.

- Pada aspek assurcane yang meliputi pelayanan customer service, kinerja 
pihak Alfacart, keakurasian proses administrasi dan penanganan complaint pelanggan, menunjukan $50.25 \%$ merasa cukup puas dengan pelayanan pihak Alfacart.

- Pada aspek emphaty yang meliputi perhatian terhadap pelanggan individu, kesungguhan dalam merespon pelanggan, perhatian yang sama kepada semua pelanggan, waktu respon dan mekanisme penanganan complaint pelanggan, menunjukan $41.79 \%$ responden merasa cukup puas bahkan puas dengan emphaty pihak Alfacart kepada pelanggan.

\section{DAFTAR PUSTAKA}

Anna Ardhi Putra. (2012). Android dan

Anak Tukang Sayur, Buku Praktis Belajar Pemrograman Android. Lubuk Linggau. Wartech-id.com.

B. Andreas. 2011. Organisasi : Menuju Pencapaian Kinerja Maksimal. Jakarta : Prasetya Mulya Publishing.

Annalee Newitz (2000). "The Personality Paradox", The Industry Standard, 2 Oktober 2000, h. 210 - 14, dikutip dari
Ivancevich, J.H., Konopaske, R., \& Matteson, M.T. (2007). Perilaku dan Manajemen Organisasi. Jakarta : Erlangga.

Ahmadi, C dan Hermawan, D.2013. EBusiness \& E-Commerce. CV.Andi Offset, Yogyakarta.

Dillon, William, R., \& Goldstein, Matthew. (1984). Multyvariate Analysis, Methods and Applications. New York.

Gary Growth - Marnat. 2009. Handbook of Psychological Assessment. Yogyakarta : Pustaka Pelajar.

Gosh S.1998, Making Business Sense Of The Internet Harvard Business Review, March -

Hamill J and Gregory.K, 1997, Internet Marketing in The Internationalization of UK Smes, Journal of Marketing Management, Vol.13,pp.9-28.

Hofman D.L and Novak, 2000. How to Acquire Customers on The Web. Harvard Business Review, MayJuni, pp.179-188.

Hakim, Abdul. (2001). Statistika Deskriptif untuk Ekonomi dan Bisnis. Yogyakarta. 